\title{
EL HOMBRE PALABRA Y LA MUJER TRAICIÓN EN LA “LA CILINDRA" DE CARMEN BÁEZ ADRIANA SÁENZ VALADEZ
}

\section{Espacios y luchas femeninas. Usos y apropiaciones espaciales en la Costa Chica}

Nuria Jiménez

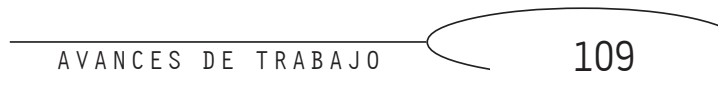


${ }^{1}$ Sirva este texto de homenaje a una escritora que contó con varios premios a su labor cuentística y que en la actualidad es poco leída. ${ }^{2}$ Agradezco los comentarios que este trabajo, en una versión preliminar, recibió en el Congreso de Literatura Mexicana "Entre dos Centenarios", organizado por la Universidad Autónoma Metropolitana, Iztapalapa. asaenzva@gmail.com Universidad Michoacana de San Nicolás de
EL HOMBRE PALABRA Y LA MUJER TRAICIÓN EN “LA CILINDRA" DE CARMEN BÁEZ ${ }^{1}$

ADRIANA SÁENZ VALADEZ2

\section{Resumen}

En este trabajo se lleva a cabo un análisis del cuento "La Cilindra" de Carmen Báez. Para ello la metodología propuesta está en el contexto de la filosofía, la literatura y la teoría de género. En este marco se tiene como hipótesis que la autora a través de los recursos literarios realiza una reflexión crítica de los prototipos de género, asumidos como ideales imposibles de cumplir, esto es, que en la relación dialéctica que mantienen la vida vivida y la ficción, los esquemas se asumen, construyen y reproducen desde los supuestos que la racionalidad patriarcal ilumina en la vida vivida y por ende en los productos culturales.

Para analizarlo, el artículo se ha dividido en cuatro apartados. En el primero se aborda el concepto de prototipo en la Revolución. En el segundo se estudian los esquemas del ser mujer en "La Cilindra". En el tercero se analizan a Juan Lanas y a su superior como dos formas de ser varón durante el movimiento armado y finalmente se propone un análisis de los elementos expuestos. 
Palabras clave: prototipos, Revolución, género, feminidad, masculinidad, Carmen Báez, ficción.

\section{Abstract}

Through the tools of philosophy and gender studies, this work is carried out as an analysis of the story "La Cilindra" of Carmen Baez. For this is the hypothesis that the author through literary devices makes a critical reflection of gender prototypes, assumed to fulfill impossible ideals. This is, in the dialectical relationship that lived life and fiction have, the schemes are assumed, constructed and reproduced from the patriarchal rationality assumptions that glows vivid life and therefore in cultural products.

This article has been divided into four sections. In the first, the prototype concept is discussed in the revolution. In the second, schemes of womanhood are studied in "La Cilindra". In the third, Juan Lanas and his superior are analyzed as two ways of being male during the armed movement and finally an analysis of the elements exposed is proposed.

Keywords: prototype, Revolution, gender, femininity, masculinity, Carmen Báez, fiction.

RECEPCIÓN: 6 dE OCTUBRE dE 2015 / ACEPTACIÓN: 20 DE NOVIEMBRE DE 2015 
EL HOMBRE PALABRA Y LA MUJER

TRAICIÓN EN “LA CILINDRA” DE

CARMEN BÁEZ

En este trabajo se lleva a cabo un análisis del cuento "La Cilindra" de Carmen Báez. Para ello la metodología propuesta utiliza herramientas de la filosofía, la teoría de género, y la literatura. En este marco se tiene como hipótesis que la autora a través de los recursos literarios realiza una reflexión crítica de los prototipos de género, asumidos

${ }^{3}$ Para una propuesta donde se estudia la posibilidad de hacer preguntas filosóficas desde los textos literarios véase: Aureliano Ortega (2011).

"Qué pregunta la filosofía desde América" en

Cristina Ramírez Barreto (Coord.) Filosofía desde América: temas, balances y perspectivas. Quito, Ecuador: Editorial Abya Yala, pp. 17-44. En este vértice se encuentra la propuesta que se plantea en este artículo, donde se expone que se pueden hacer análisis críticos del devenir patriarcal a través

del estudio, desde la perspectiva filosófica de género, de las ficciones. como ideales imposibles de cumplir, esto es, que en la relación dialéctica que mantienen la vida vivida y la ficción, los esquemas se asumen, construyen y reproducen desde los supuestos que la racionalidad patriarcal ilumina en la vida vivida y por ende en los productos culturales ${ }^{3}$.

Con este propósito y motivada por los objetivos expuestos, el artículo se divide en cuatro apartados. En el primero se aborda el concepto de prototipo en la Revolución. En el segundo se estudian los esquemas del ser mujer en "La Cilindra". En el tercero se analizan a Juan Lanas y a su superior como dos formas de ser varón durante el movimiento armado y finalmente se propone una síntesis de los elementos abordados. 


\section{PROTOTIPOS EN LA REVOLUCIÓN}

La Revolución, con sus cambios políticos y culturales, incorporó elementos en la construcción de la cultura nacional. Estas modificaciones estuvieron enmarcadas por algunos de los cuestionamientos que el proceso de modernización trajo consigo, algunos como los cuestionamientos sobre la identidad del ser mexicano fueron interrogantes que bordaron con su aroma dichos tiempos ${ }^{4}$.

${ }^{4}$ Hubo varias respuestas a estas interrogantes, entre ellas las que hicieran Samuel Ramos o más adelante los integrantes del grupo Hiperión, incluso Octavio Paz.

En ese devenir histórico cimentar ideológicamente la edificación de una nación fue una labor compleja. En este proceso el lenguaje cotidiano, las ficciones, los estudios filosóficos, las posturas políticas, entre muchos otros elementos; colaboraron en la tarea de construcción y crítica de esta edificación simbólica y en el marco del proceso revolucionario y posrevolucionario impactaron el devenir cultural. Así, en el transcurrir entre el pensar al/a la mexicano/a y la realidad cotidiana que se enfrentaba, se llevaron a cabo, desde los productos culturales, algunas propuestas, como la que motiva este análisis.

En la vida que se afrontaba en medio de las guerras de Revolución se establecieron cuestionamientos importantes para los prototipos de género, ante esta nueva realidad, ¿cómo saber qué implicaciones y deberes tenían los hombres y las mujeres frente a esta nueva forma social? ¿Qué cambios se debían asumir como parte de la nueva identidad? En este sentido, a 
través de diferentes tecnologías surgieron prototipos de género, en tanto ideales a imaginar, esquemas que estuvieron en mucho delimitados por la tradición y la racionalidad teológica.

Desde esta noción y para efectos de este análisis es importante la comprensión de lo que sustentaremos por prototipos de género, ya que el concepto está en el vértice entre lo propuesto por prototipo como esquema y arquetipo:

...prototipos, o más específicamente de prototipos de hombres y de mujeres, tendría que analizarse, en el ámbito de la semántica, como resultado de un proceso de categorización que realizan las personas en las experiencias cotidianas de interacción discursiva. Podemos pensar, en este caso, en los prototipos como procesos cognitivos compartidos en la interacción entre humanos, es decir, en cognición socialmente compartidos que resultan en la categorización prototípica (Pérez, 2011: 48).

Si bien esta definición es puntual y pertinente, para considerar el presupuesto como un proceso semántico y un acuerdo social es necesario trenzarla con algunas de las variables de la categoría arquetipo, que para un estudio histórico plantea Julia Tuñón. 
Los arquetipos son conceptos fuertes y elementales de muy larga duración que remiten a construcciones imaginadas que tienen que ver con las pulsiones básicas de los seres humanos. El concepto de arquetipo es delicado para el trabajo histórico, atento a los cambios humanos, tanto sociales como culturales, porque ha sido asociado a una estructura fija de la psique humana. En este libro el término no se piensa como de naturaleza, pero se utiliza porque sugiere categorías mentales fundamentales para la cultura, de muy larga duración. Así, sin considerarlo natural o eterno, se observa aquí como una continuidad en relación con la construcción de los géneros... (1998: 76).

Si bien ambas propuestas demarcan que los prototipos (asumamos, a partir del análisis que realiza Tuñón, que los arquetipos pueden ser también comprendidos como prototipos) son categorías del deber ser humano, en cuanto a los géneros (entendidos desde la postura de Judith Butler $)^{5}$ el primero atiende a lo espe${ }^{5}$ Véase: Judith Butler (2006). Deshacer el género. cíficamente delimitado como campo Barcelona: Paidós. semántico, en tanto categoría definida por la cultura, mientras que en el segundo, a pesar de la pertinente aclaración de la autora, resulta difícil mantener una lectura desligada de la postura esencialista del concepto, dado que tiene su raíz en el pensamiento psicoanalítico. 
Así, para efectos de este análisis, desde la conjunción de ambas propuestas, los prototipos se comprenden como una noción, una sustancia en el mundo de las ideas, en tanto concepto imaginado, que implica que en la praxis es imposible de cumplir, pero que con su ethos delinea los deberes ser para los géneros, en tanto esquema normatizador y naturalizador de los seres humanos. Este esquema, a pesar de que tiene la capacidad de devenir muy lentamente en el tiempo y en los contextos culturales, conserva su característica de cognición social compartida, puesto que es imaginada y simbólica y, por ello, colabora en el proceso continuo del género.

Los prototipos como esquemas de género están formados por los ethos, las nociones que la racionalidad patriarcal sustenta, con lo que, pese a la movilidad que tienen en el tiempo, en mucho conservan sus raíces simbólicas. Lo que lleva a que, aun cuando las prácticas se modifiquen, en mucho se continúan asumiendo los mismos ethos y con ello a los prototipos como anhelos. En esto se sustenta que se comprendan como modelos en tanto se codifican como ideales.

\section{EL MOVIMIENTO ARMADO}

El movimiento armado, como una de las realidades vívidas del tiempo, de manera dialógica, con los textos culturales $^{6}$, aportó elementos que se instauraron en las imágenes simbólicas, en los prototipos del deber ser. 
La ficción colaboró en esta tarea múltiple: contribuyó para que estos eshistóricos, sociológicos, antropológicos, etc., y de las llamadas ciencias exactas, que pretendan explicar quemas se reprodujeran como ideales, incorporó las representaciones que estaban en la cotidianidad $y$, con sus modificaciones, las asumió en la categoría de ideales, y quizá de manera menos frecuente realizó crítica de estos esquemas.

Artistas e intelectuales que se sentían amenazados convirtieron a las mujeres en arquetipos tradicionales que podían controlar. Pudieron salirse con la suya porque, como señala Monsiváis, el machismo voraz de la guerra casi logró eclipsar un incipiente movimiento feminista (Kay, 2009: 45).

Como parte de la situación bélica, la forma de enfrentar la muerte fue una de las características del vivir la vida. "No hay sino dos opciones, o te mueres o te matan (1910-1920). Ser macho durante la etapa álgida de la Revolución no es mérito extraordinario porque todos necesitan serlo, al requerir sobrevivencia agallas, coraje, güevos (...)" (Monsiváis, 2004: 93). Así, la actitud frente a la muerte fue uno de los elementos que delimitaría la masculinidad de los varones revolucionarios. La forma de vivir la muerte, de vivir sin miedo, conformó la vida. No se debía vivir temiendo porque eso no era vida. La muerte fue un personaje y un mecanismo que delimitó la existencia, 
un elemento a temer $y$, en esta encrucijada, vivir controlando las emociones.

La ficción ante este proceso no fue un bloque ideológicamente homogéneo. Unos en medio de la discusión retrataron imágenes bañadas por el ethos teológico del deber ser y lo

${ }^{7}$ Un ejemplo de esta concepción se encuentra en Federico Gamboa (2001). Santa. México: Época.

${ }^{8}$ En su mayoría los escritores de la generación de 1929, quienes ya miraban el movimiento bélico con cierta distancia (Sáenz, 2011: 146-150).

${ }^{9}$ Véase: Celia Amorós (2009). "Rousseau, teórico de la virilidad política" y "Rousseau teórico de la feminidad normativa" en Vetas de Ilustración. Reflexiones sobre feminismo e islam. Madrid: Ediciones Cátedra, pp. 73-78. Y Juan Jacobo Rousseau (2007). El Emilio o de la educación. México: Ed. Porrúa, Sepan Cuántos. Núm. 159. establecieron como lo debido para los hombres y las mujeres ${ }^{7}$. Otros hicieron crítica de estos prototipos y retrataron distintas imágenes que vislumbraban otras formas de existir ${ }^{8}$. En este sentido, Carmen Báez mostró concepciones arraigadas en el deber ser de una racionalidad ilustrada ${ }^{9}$ que mantenía muchas de las formas mo-

rales de la racionalidad teológica. Con lo que evidencia que la razón moderna había traído consigo semillas que habían

${ }^{10}$ Rolando Casale y María Luisa Femenías hablando del deseo en Butler especifican que la modernidad no es un proyecto ideológico inacabado, sino imposible de terminar, por ello postulan por la posmodernidad como una propuesta que se distancia de la modernidad en cuanto a su proyecto de razón totalizadora. Véase: (2009).

"Breve recorrido por el pensamiento de Judith Butler" en Casale, Rolando y Chiachio, Cecilia (Comps.). Máscaras del deseo. Una lectura del deseo en Judith Butler. Argentina: Catálogos, pp. 11-37. germinado y, en su fruto, en lo más íntimo de su pensamiento, había permanecido la costumbre ${ }^{10}$.

Para algunos/as la vida era vivir sin miedo y con miedo, en la apariencia y en la máscara. Los esquemas para los hombres y las mujeres se estipularon en términos dicotómicos tanto en elementos de valor como de género. Los hombres debían ser valientes porque de lo contrario eran cobardes; vencedo- 
res o vencidos, soldados o intelectuales. Para las mujeres la propuesta no estuvo delimitada por el arrojo, sino por la ternura y el afecto, entre otros aspectos. En cuanto a los prototipos, principalmente fueron mujeres en conyugalidad, madres, soldaderas, hijas, “...cocineras, enfermeras, amantes (...), barrenderas, enterradoras..." (Kay, 2009: 43), campesinas; con menor énfasis "Misses" (Bastian, 2006: 163180), y en el caso denostado mujeres públicas sexuadas ${ }^{11}$.

El movimiento armado puso a los hombres frente a las balas y con ello se asumió el deber ser del "macho"12. Debían enfrentar las balas sin miedo y si lo tenían nunca decirlo, ya que de hacerlo se pondría en cuestión su identidad de varón. El cuestionamiento para los hombres era en términos de la virilidad, por eso en sus acciones y actos del lenguaje debían todo el tiempo constatar y comprobar su condición.

Para las mujeres el movimiento armado también impuso formas de vivir el deber ser, para lo cual algunas
${ }^{11}$ Si bien los estudios históricos actuales con perspectiva de género han estado recuperando la historia de las mujeres de la época que participaron como generalas, soldados o líderes de algún sector del movimiento armado, no se puede afirmar que estos modelos fueran una opción que todas las mujeres pudieran elegir, ni se puede decir tampoco que aquellas que recusaron los roles tradicionales evitaran pagar sanciones morales por sus decisiones. Para ejemplos de casos documentados de mujeres que rompieron con los roles tradicionales véase el libro de Gabriela Cano, Mary Vaughan y Jocelyn Olcott (Comps) (2009). Género, poder y política en el México posrevolucionario. México: FCE. Si bien casos de mujeres que se asumieron diferentes a los prototipos patriarcales existieron, el sentido moral de la racionalidad patriarcal continuó siendo predominante. Kaplan evidencia como para el caso de la clase trabajadora el derecho masculino al poder en el ámbito privado fue un elemento que frenó al movimiento gremial “... los hombres de la clase trabajadora llegaron a un pacto con el Estado, cambiando su poder de organización e independencia por el derecho al control privado sobre mujeres y niños" (Kay, 2009: 52).

${ }^{12} \mathrm{El}$ concepto del macho está asumido como un prototipo y, por ende, entre otras variables muta con el tiempo y la delimitación geográfica. Vale decir que el "macho" también está atravesado por la intersexualidad, raza, clase, situación geográfica e incardinamiento (desde la postura de Braidotti), esto es, por muchas variables que lo modifican y lo hacen en lo vivible, como todo prototipo, imposible de encarnar, pero sí posible de anhelar. Vale decir que para este tiempo la connotación de ser macho implicaba valentía, no tenía comprensiones desde lo que el patriarcado ha asumido. "Ya en la etapa de la industrialización el machismo (el término que denuncia o elogia una conducta) se va convirtiendo en "mala palabra", delatadora de actitudes vandálicas y señal de anacronismo sin remedio (entonces lo contrario del macho es varón, término igualmente patriarcal pero más contenido en cuanto a su vocación de arrasamiento) (Monsiváis, 2004:95). 
debieron y otras pudieron masculinizarse, "machificarse"

${ }^{13}$ En la Revolución la mujer pudo sacar todo lo
masculino que había en ella y proyectarlo al varón
(Ramírez, 2004: 71).

(Monsiváis, 2004: 94; Rubenstein, 2006: 91-126 y Cano, 2006: 61-90) ${ }^{13}$. Si bien la masculinización fue una opción de sobrevivencia femenina, las mujeres debían tener cuidado, en el ámbito de la conyugalidad, de no llevar a cabo este cambio, porque implicaba la transposición de las figuras simbóli-

\begin{abstract}
${ }^{14} \mathrm{Al}$ hablar de balance no se presupone equidad ni equilibrio, sino la forma de vivir las identidades frente y desde el poder. En este sentido se asume que los roles mantenían un "equilibrio" en el ámbito de la conyugalidad porque se delimitaban

figuras simbólicas, deberes y labores a partir del sexo, en la evidente desigualdad, ya analizada, que ello conlleva.
\end{abstract}

cas. Ante la cotidiana violencia la tentación de la transposición era grande, pero igual el riesgo. En caso de hacerlo ponían en cuestión el orden impuesto por esta racionalidad ${ }^{14}$ y en este sentido debían asumir la sanción de dicha infracción al orden moral.

Si bien los esquemas para la mujer no fueron todos iguales, cada uno de estos sí estaba cuidadosamente delimitado por

\footnotetext{
${ }^{15} \mathrm{Si}$ bien no existe una sola postura con respecto a los roles que las mujeres ocuparon, sí se conoce que se diferenció por clase social, ubicación geográfica, educación y familia. "Las revolucionarias conocidas son por lo común señoras y señoritas de clase media y alta que fundan clubes antigubernamentales y discuten alternativas a la dictadura. En cuanto a las mujeres de estratos populares la violencia múltiple desencadenada en su contra explica su participación escasa en las movilizaciones. Su inmovilidad laboral y social provoca su desinformación, que es el principio y el fin de su despolitización" (Monsiváis, 2009: 14)
} ellas estaba en la vida moral y, si su deber ser, a manera de esquema de la vida ${ }^{15}$. El cuestionamiento para incumplían el rol, vivirían el estigma de la inmoralidad; mientras que para los hombres el cuestionamiento era en el ámbito de la identidad. Debían afirmar en cada acto su ser masculino, si no cumplían con este modelo debían vivir estigmatizados, fuera de la subjetividad aceptada, se les conocía como 
poco hombres y a las mujeres como descarriadas. La paradoja se sitúa en la posición del juicio, el mismo acto no se representaba ni se castigaba desde el mismo plano, sino que se separaba y se enjuiciaba distinto.

El movimiento armado apoyó la mitificación de la figura femenina. A través de diferentes esquemas se naturalizaron concepciones de la feminidad y se asumieron como el hacer y ser de las mujeres. Uno de los prototipos que más se enraizó fue el de madre y sus deberes de hacer, todo como herencia del pensamiento teológico. La función nutricia que está en el marco de lo biológico pasó a ser uno de los elementos fundacionales del ser mujer; la aporía consistió en que la concepción pasó a formar parte del ser mujer; se naturalizó la noción como una sustancia de la feminidad; se asumió como ontológico y en ello se le reconoció y enalteció.

A las mujeres se les pensó como seres esencialmente naturales, capaces de generar el lazo primigenio y desde esta perspectiva a partir de lo teológico se les catalogó como "buenas y correctas", por esencia mujeres. Fueron las dadoras de vida y las encargadas del cuidado de los otros. En esta aporía metonímica se les asumió para cumplir ciertos prototipos. Con base en dicha función se les delimitó en el espacio privado, se les excluyó en muchos casos de ciertos niveles de escolaridad, se les postuló sólo realizando funciones en el marco de la familia y desde ahí se les permitieron ciertos haceres. Además, no se pensó que estas actividades que están inmersas en 
el ámbito cultural fueran productoras de cultura, de conocimiento y de leyes, se deliberó que esas labores eran de los varones; por ello, las mujeres quedaron excluidas del ámbito de las decisiones, por lo menos así fue para la mayoría.

\section{"LA CILINDRA": DOS ESQUEMAS FEMENINOS EN OPOSICIÓN}

Carmen Báez fue una escritora michoacana que destacó en la poesía y el cuento; ejerció la diplomacia y el periodismo y "tuvo a su cargo la Dirección de Cinematografía de 1958 a 1964" (Almazán, 2010). En 1955 ganó el "Premio Nacional para el mejor cuento con 'Dos o tres meses'" (Leal, 1976: 115). Dada su trayectoria en 1993 se creó el Premio Nacional de Cuento que entregaba ConACUltA, el cual llevaba su nombre ${ }^{16}$.

${ }^{16}$ Véase: Laura Almazán (2010). "La escritora Carmen Báez cumple 100 años" en "Escenarios” en Cambio de Michoacán. Sociedad Editora de Michoacán S.A. de C.V. 20 de febrero de 2010. (Recuperado de http:// www.cambiodemichoacan.com.mx/ vernota.php?id=118895).

${ }^{17}$ Para efectos de esta propuesta las referencias se harán de: Carmen Báez (1976). "La Cilindra" en Luis Leal. Cuentos de la Revolución. México: UNAM, Biblioteca del Estudiante Universitario.
Cabe señalar que dicho reconocimiento se otorgó durante más de 16 años. A pesar de dichas distinciones, en la actualidad Carmen Báez es una escritora poco leída.

"La Cilindra" se publicó en 1946 en la Antología de Cuentos mexicanos de autores contemporáneos ${ }^{17}$. En él la autora hace un retrato costumbrista de la vida de una pareja que está en la lucha revolucionaria. Por ello, a partir de la metodología de género, se analiza el cuento para explicar la relación entre la literatura como un discurso mediante el cual se pueden construir, re- 


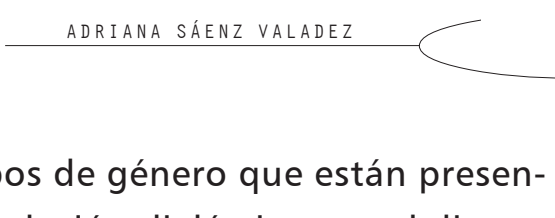

producir y proponer prototipos de género que están presen-
tes en la cultura y que en la relación dialéctica con el discurso se viven, se enseñan y se continúan.

La mímesis del cuento está ubicada en la Revolución. Por medio de unidades como la metáfora y la personificación, referida a manera de sinestesia - formas comunes de las fábulas - se desarrolla la historia. La ficción está narrada a través de un sujeto de enunciación extradiegética, con algunos elementos de narrador omnisciente. En éste, a través de varios mecanismos literarios como los tropos, se personifica a la Cilindra de tal manera que se hace una comparación ficcional con la Marota, la esposa de Juan Lanas. De este modo, a través de la ficción se lleva a cabo una reflexión crítica de los prototipos de género.

Por medio de varios personajes se van configurando los esquemas, uno es Juan Lanas, revolucionario de uno de los bandos armados, bien a bien no se sabe de cuál, mas a partir de las descripciones, los usos y costumbres, los valores y las acciones se conoce que es un soldado. La Cilindra es la perra que sigue a Juan a todos lados. La Marota es la esposa del militar, compañera celosa del aprecio de Juan por la Cilindra. La mujer es un personaje que representa el prototipo de la señora que falla porque incumple con el deber ser de su prototipo. Los compañeros del ejército son hombres que en esta singularización del plural fungen como observadores y actores de esta historia que termina en tragedia, con la muerte 
física del héroe y simbólica de la heroína, quien a través del recurso de la sinestesia adquiere características humanas.

Uno de los cuestionamientos que subyace en "La Cilindra" es ¿cómo una mujer en tiempos de la Revolución pudo traicionar a su hombre $y$, desde la perspectiva patriarcal, actuar contrario a lo que su ser natural, de ser mujer, propone? Con lo que se explicita que los esquemas dados a las mujeres estaban delimitados por la concepción de la diferencia sexual y, en ello, coloreados por preconcepciones de figuras míticas, imposibles de existir en lo cotidiano, sustentadas en preconceptos teológicos, pero que cimentaron algunos de los conceptos del ser mujer en la Revolución.

A través de la diégesis y de los tropos literarios, la Marota y la Cilindra son dos figuras femeninas que compiten por el

${ }^{18}$ Véase: Adriana Sáenz (2015). "La crítica a la racionalidad patriarcal, un paradigma para pensar a los géneros" en Virginia Ávila y Paola Suárez (Coords.) El género y la globalización en los debates de la Teoría Social Contemporánea. México: UNAM, pp. 84-109. efecto de Juan Lanas. Representan a las mujeres que estaban inmersas en los esquemas ideales promovidos por esta racionalidad ${ }^{18}$. A partir de sus representaciones se delinean dos elementos que constituían el ser mujer: por un lado, la diferencia sexual, asumida como aquel instinto dado por la biología que hacía que las mujeres actuaran de determinadas maneras, algunas por ejemplo son el deseo "natural" por la maternidad, que incluye el amor por los hijos, el goce por el servicio a los otros, la dulzura y la paz; por el otro, la educación, las mujeres eran enseñadas a competir y celarse, porque desde esta 
perspectiva las relaciones solidarias y de apoyo no se contemplaban ni se favorecían.

Desde estos esquemas promovidos por el pensamiento patriarcal que cautivaba el ser mujer desde lo propuesto por la diferencia sexual — que posicionaba a las mujeres como madres, obedientes, brindadas, tiernas y pacíficas por naturaleza- se castigaba a todas aquellas que no se incluyeran en dichos modelos. Por igual, desde la educación las mujeres aprendían a pensarse y pensar a las otras como amenazas, que las llevaban a competir y a no desarrollar, mayoritariamente, conductas de solidaridad.

A partir de estos esquemas, una de las formas del ser mujeres que se propuso, cuya noción estaba sustentada en las concepciones heredadas de la racionalidad teológica, implicaba ser desconfiada y celosa. Debían competir como una forma de demostrar y obtener el amor de aquel varón por el cual pugnaban. Este mecanismo de rivalizar por el afecto, el amor o el cuidado era una forma común de conducta femenina. En este sentido moral de competencia y merecimiento, Juan puede cambiar a una por la otra. El varón patriarca en la masculinidad tradicional no ama a una mujer en lo individual, sino la concepción que ha aprendido de la feminidad y en consecuencia debe actuar a partir de lo acostumbrado.

En el cuento ambas figuras femeninas están compitiendo por el afecto y el reconocimiento del soldado. Entonces, en el transcurrir del relato, la Cilindra, quien ya ha demostrado su 
lealtad a la causa, tiene amoríos con el Capulín "un perrazo negro" (Báez, 1976: 116), relación de la que procrea dos cachorros que, a decir del narrador, "...por desgracia nacieron en el cuarto de Juan Lanas" (Báez, 1976: 117). Es importante mencionar que, a partir del nacimiento y del espacio donde se lleva a cabo, se agudiza el conflicto. Entran en el ámbito de la batalla varios elementos simbólicos delimitados por esta razón. Se agregan a la competencia, ya establecida como natural, la maternidad y los espacios de interacción dados a cada figura femenina.

La Cilindra es la compañera de las batallas, la que se ha ganado el respeto de todos:

...en su hoja de servicios tenía anotada más de alguna acción de armas en la que tomó parte tan activa como los hombres, como las mujeres. Nunca conoció el miedo y ante el enemigo se ponía furiosa, tan furiosa que hubiera sido difícil vencerla a ella sola (Báez, 1976: 116).

La Marota pertenece a otro espacio, el privado, el del afecto. En esta delimitación simbólica de las áreas, la Cilindra invadió el lugar de intimidad entre Juan y la Marota. Con este acto se cierra el círculo de la afrenta y se establece la batalla, elemento que llevará al desenlace. 


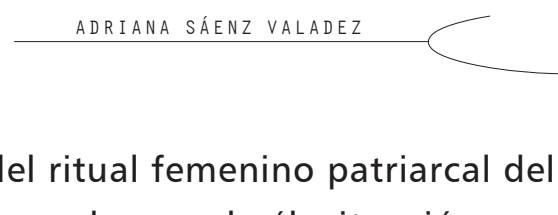

La competencia es parte del ritual femenino patriarcal del amor. Ellas deben competir por el amor de él, situación que desde esta moral se percibe como natural. Las mujeres en dicha época debían demostrar con actos su participación en dicha rivalidad. El ritual amoroso implicaba para el ámbito femenino insertarse en la batalla del afecto. Esta cruzada implicaba celarse y evidenciar los elementos de superioridad de una sobre otra. Para esto los espacios estaban delimitados simbólicamente. Una es la mujer del espacio privado, la Marota, la compañera de la vida de Juan. La Cilindra es la compañera solidaria del espacio público, el de las batallas. Así, mediante la división de los espacios ambas mujeres podían continuar la rivalidad por el afecto, pero ambas podrían legítimamente pertenecer a la vida de Juan.

Cuando la Cilindra tiene a los perritos adentro en el espacio delimitado para la Marota, se rompe el equilibrio de las rivalidades, ella se ha inmiscuido - simbólicamente- entre Juan y su esposa, situación que la Marota, que deseaba cumplir con el deber ser de esposa, no podía permitir. La esposa idealizando el prototipo desea cumplir el deber ser y está ante una encrucijada: vivir la maternidad de la perra o, en el ritual amoroso por Juan, continuar celando y peleando.

La decisión que asume rompe con las reglas "válidas" de la batalla, lleva a cabo conductas que no son pensadas como femeninas, y en ello se rompe el ritual amoroso, no actúa según lo esperado y, para continuar la cruzada, actúa a partir 
de una conducta de muerte, elemento que la lleva a la degradación y a la pérdida de la pelea. La Marota no sólo no actúa según lo establecido para lo femenino, sino que en los celos se masculiniza, intenta matar a los perros.

La muerte, elemento que en tiempos revolucionarios y en la ficción de la época era un tema recurrente, no estaba fuera de las formas del vivir, pero era un elemento predominantemente masculino, considerado "de los hombres", por ello la decisión de la Marota de aventar a los cachorros al río la masculiniza, porque al ser una posibilidad pensada para el ser varón, era una aporía, desde el pensamiento de la diferencia sexual, en el ser femenino.

La Marota rompió con el deber ser para lo femenino, con el pensamiento del ser mujer de la diferencia sexual, y con el ritual amoroso de vivir compitiendo por el amor de Juan, pero siempre desde las reglas delineadas por el deber ser del patriarcado. Este acto de la Marota provoca que Juan se perciba afectado en su imagen de varón. Juan a partir de este hecho ya no asume a la Marota como su esposa "ideal", sino como un ser masculinizado, situación que, en lo metafórico, modifica las concepciones del deber ser y del poder, elementos que nos trasportan al final del cuento.

La Cilindra, sin perder tiempo se lanza al río para salvar a sus cachorros y Juan Lanas va tras ella. Entre ambos logran salvar a los cachorros. Con este acto se ejemplifican, una vez más, las dualidades simbólicas de los deberes ser para los gé- 
neros. Juan, personaje prototipo de esos tiempos, prefirió lo que había aprendido como el deber ser, a la madre que a la esposa. Desde este enfoque la Marota se percibe denigrada.

A consecuencia de este acto, que conlleva la intención de matar a los cachorros, Juan Lanas golpea a la Marota — debe aprender a ser esposa y mujer-. Ella debe asimilar cómo ser mujer, que involucra competir, ser madre y por supuesto nunca actuar como aporía de lo femenino, no puede (desde el pensamiento patriarcal que naturaliza el ser mujer) ni debe masculinizarse. La esposa debe comprender que su conducta debe estar delineada por los deberes de lo femenino, de lo contrario, se asumirá que no sólo está traicionando los conceptos de la conyugalidad, sino aquellos supuestos patriarcales que son pensados como ontológicos, los propuestos que naturalizan el ser mujer, pero que en realidad son culturales.

En este sentido a la madre se le premia su actuar. En esta racionalidad y en dicha época las mujeres debían ser madres, se presuponía que serlo era lo natural, pero también debían asumir la maternidad como lo principal de sus vidas. Se comprendía, desde dicha naturalización, que ser madre era un sinónimo de ser mujer. Lo que nos lleva a considerar otra variable que está implicada en esta representación. La mirada de los otros y las otras. Aquellas que cumplían con este supuesto y asumían, según los ojos de los/as demás, dicha representación, de tal manera que contaran con la aprobación de los/as 
otros/as, se les retribuía otorgándoles poder, reconocimiento y obediencia.

Desde estos actuares, la Marota, llevada por los celos y pretendiendo ganar la batalla, rompió con la concepción del ser mujer y ahora deberá asumir las consecuencias de tal error. A partir de este momento la batalla por el afecto de Juan está a favor de la Cilindra, que era fiel, brava y, ante todo, madre.

\section{DOS FORMAS DE MASCULINIDAD ${ }^{19}$}

Juan Lanas y el Comandante representan dos formas de masculinidad en tiempos revolucionarios ${ }^{20}$.

\footnotetext{
${ }^{19}$ La construcción de lo que implica ser hombre viril es una pluralidad de sentidos y significados. "El

'sujeto' masculino es una construcción ficticia producida por la ley que prohíbe el incesto y obliga a un desplazamiento infinito de un deseo heterosexualizador" (Butler, 2001: 61).

20 "La masculinidad no existe, me encontré diciendo: sólo hay masculinidades, muchos modos de ser hombre" (Thompson, 2005: 11).
}

Ambos se encuentran inmersos en las leyes de la milicia que tienen en sí mismas sus propios códigos de lo valioso, tales como la lealtad y la sumisión. El Comandante cumple con la función encomendada, hacer cumplir la ley marcial a todo traidor, incluso aquel que lo hiciera por hambre, miedo o dolor; cualquier deslealtad se debía pagar con la muerte, si no, ¿en qué se sustentaría la lealtad al ejército y su poder? No bastaba con el pago y el honor, el miedo fue un gran aliado.

La figura del esposo está descrita: “...aquel Juan Lanas, que era borracho y bueno, pero también era traidor. Su misma mujer vino a contarlo" (Báez, 1976: 117). En esta época el hombre debía comprobar su masculinidad en todos sus actos, golpear 
a su pareja era una forma pública de hacerlo, de otro modo, ¿dónde quedaría él como varón, si lo otros veían que ella no lo obedecía? Y sobre todo se masculinizaba de manera pública, con lo que simbólicamente se transponían las fuerzas, los roles y el poder.

A través de las interacciones de los personajes masculinos con los femeninos se delinean esquemas de los varones. Juan podía ser golpeador, borracho, bueno, valiente, competitivo, debía mantener una actitud siempre defensiva y demostrar que él sí sabía cómo se hacían las cosas (Millington, 2007: 37). Desde los prototipos para la masculinidad que se propusieron en dicha época, Juan debía golpear a la infractora para hacer cumplir su ley y demostrar su ser "varón". Desde este acto se evidencia una vez más la importancia de la mirada y el reconocimiento de los/as otros/as. El soldado golpea a la Marota como una forma de enseñanza y como una forma de representación pública de que él es quien tiene el control de la vida de la pareja y que puede, además en esta nueva aporía, enseñar a la Marota a ser mujer.

Juan cumple con casi todos los elementos de la masculinidad; no le tiene miedo a la muerte y lo sabemos porque no aboga por su vida, sino por la de ella. "-Tate quieta, Cilindra -le decía Juan Lanas con voz ronca, amarga- Vete. ¿No ves que estos demonios acabarán por matarte? Déjame solito un rato" (Báez, 1976: 118). 
Las concepciones para los hombres fueron duales y aportaron elementos sustantivos en la construcción de las imágenes de género. Entre varias delimitaciones, fue importante la figura del héroe, porque definió la forma de ser hombre durante el movimiento armado. Este esquema entronó a los líderes militares, religiosos o políticos y, en esta construcción, a algunos hombres revolucionarios se les ascendió a categoría de semidioses. La memoria funcionó a partir de estos discursos y se borraron muchos de los actos de estos "héroes", en parte como una forma de legitimar un discurso "de bronce"21 $^{21}$ para crear las concepciones de la identidad nacional.

Así, a través del juicio a Juan Lanas,

${ }^{21}$ Véase: Luis González (1980). "De la múltiple utilización de la historia" en Carlos Pereyra (Coord.). Historia ipara qué? México: Siglo XXI, pp. 53-74.

22 Como dice Ramírez: "El mexicano surge a la vida con la necesidad de expresar que él es muy hombre" (2004: 77). aprendemos el deber ser de un hombre heroico y en ello nunca está decir que se tiene miedo ni cambiar de bando militar, pues ésta era considerada una actitud femenina. Se debía siempre y ante todo y todos/todas, verse valiente, "hombre"22. Se vivía escondiendo el miedo a esa vida.

Las masculinidades, desde este ideal, se vivían bajo diferentes concretizaciones de lo heroico, pero una constante que tenían era la vida anhelante del poder. Debían cuidarlo, heredarlo a "su" primogénito varón y por supuesto reproducirlo. Así se postulaba que debían vivir controlando, diciendo cómo y qué hacer. Era sustancial manejar el arma, controlar el miedo y claro está a las mujeres, de no ser así, ellas actuarían de acuerdo 
con su ser, que se postuló como "lo natural" —una vez más la concepción teológica-, quienes, desde esta perspectiva, por supuesto, harían actos de vergüenza.

Juan Lanas conoce las concretizaciones de su prototipo y de su deber ser, por ello mantiene bajo los celos y la competencia en control a la Morata. Mas en un momento que escapa a su vigilancia, el pleito entre ambas figuras femeninas lo lleva a tomar partido y la pérdida del dominio pone la piedra angular de lo que será la causa de su muerte. La Marota acude con el líder militar y lo delata infracción que no queda registrada en la ficción, por lo que se puede suponer que es falsa. Juan debe pagar con la vida el precio a su falta de poder, traicionó al grupo, a la causa, a sus compañeros, a la Revolución, todo porque su mujer lo dice. Así, el mismo acto de traición no es juzgado en ambos sexos por igual, para él es el motivo de su muerte, para ella, la aparente victoria, pues ha acusado al hombre de traición al grupo, acto no registrado, pero sí hubo una traición: la abandonó por otra aunque ésta sea una perra.

La idealización, característica del ser varón, se ha roto, Juan no es más controlador, ni hombre, ni macho, ni valiente; dicho delito derrumbó parte de su subjetividad de varón. Dominar y sujetar los pensamientos y los sentimientos fueron formas de ser hombre y Juan rompió ese pacto, no tuvo el poder de controlar todos los actos de su mujer - como nadie- pero aquí quedaron evidenciados. De tal manera que la 
Marota, en la decisión tomada por los celos, se masculinizó y con ello le restó poder a Juan. En esta transposición de las figuras simbólicas, la muerte fue la consecuencia, el justo pago a sus infracciones.

En el momento de la muerte Juan no sucumbe, no ruega por su vida, ni por otro juicio, ni siquiera por la causa; la que implora y mantiene la batalla es la Cilindra, símbolo de la fidelidad, la maternidad y, por esto, de la feminidad. En este último momento la decisión está tomada, la perra implica lo femenino, mientras que la Marota traicionó lo femenino y por tanto deberá asumir su falla. Juan no pudo controlar los celos de su esposa, debido a lo cual los elementos simbólicos entre el soldado y la Marota se invirtieron. En esa falta de poder Juan perdió hombría y la consecuencia es la muerte, por "traidor". La traición que realmente se dio fue a algunos de deberes ser del ser varón, pero la palabra de su mujer es la que se toma en cuenta, engañó a su grupo militar, todo a decir de su esposa. Ahora deberá morir.

\section{LOS MUNDOS SIMBÓLICOS}

Al verlo llegar la Cilindra, mostrándole sus dientes, le lanzó una mirada húmeda, de rabia y de ternura, de venganza, de súplica y de reto. Nunca supo el cabecilla por qué aquella mirada se le clavó tan hondo... Los ojos amarillos eran más que humanos. Estaba en ellos toda la angustia de la gleba que pedía 


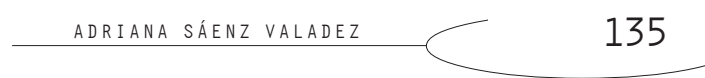

justicia, que lloraba, que sufría en silencio a veces y amenazaba con destruirlo todo.

-Que traigan a la Marota - dijo.

Cuando llegó la Marota, la mujer que traicionó a Juan Lanas, con voz ahogada dijo el cabecilla: -iMira, Marota, así defienden las perras a sus hombres! (Báez, 1976: 118).

A manera de enseñanza la Cilindra es humanizada y se explicitan las características que ha tenido a lo largo de todo el cuento. En sus ojos se encuentran los mundos, ellos reflejan e impactan al cabecilla que confiesa que "nunca los olvidará". El prototipo humanizado de la forma de ser mujer en el cuento sólo se puede comparar en tanto se asuma como lo naturalmente femenino porque, a pesar de que la Cilindra sigue siendo una perra, lo naturalmente femenino se enaltece pues, como lo dice el líder: "-iMira, Marota, así defienden las perras a sus hombres!" (Báez, 1976: 118).

En el relato la figura de la Cilindra tiene varias acepciones semánticas. La primera es la compañera solidaria que ha acompañado al soldado a lo largo de las batallas, otra está en un aparente sentido peyorativo, es una perra, no es humana pero, a pesar de ello, está en la escala del poder sobre la Marota, que no sabe cómo ser mujer.

En la ficción, la heroína rompe con los elementos de la heroicidad que es por antonomasia posibilidad del varón. La Ci- 
lindra ama más la vida del "otro" que la suya y por ende lo heroico y se puede decir lo femenino, en términos de la entrega por los otros, del animal. A pesar de todo muere en la inmolación y se completa el proceso del círculo que mitifica y

23 "El concepto tradicional de héroe es excluyente y no concibe a las heroínas. El heroísmo, en las definiciones de textos de historia, novelas y discursos, es por fuerza masculino. El héroe puede ser santo y sabio, pero la sustancia primordial es la capacidad de salvación de los demás. Guerrero, revolucionario, disidente, con gran frecuencia es sacralizado por el derramamiento de sangre. La tragedia en la que se sumerge lo humaniza y, al mismo tiempo, lo diviniza" (Monsiváis, 2000: 82). da sentido a la heroicidad, el deber ser está cumplido y ella es puesta en dicho esquema ${ }^{23}$, se le premia con el reconocimiento y la exaltación. La Cilindra paga con la vida su lealtad, muere asumida, mitificada a través de ser una mujer; en tanto afecto, dulzura, entrega, es puesta en el prototipo de lo femenino.

La Marota paga con la degradación su deslealtad. Debe ser deshonrada porque es el justo abono a su traición. La traición no fue que acusó a Juan Lanas, sino que se masculinizó, contrarió el deber ser femenino. En la espera de ganar en la pelea simbólica de la feminidad-celos, contradijo el ethos asumido para lo femenino. Así, la retribución a la traición al deber ser de la feminidad la da la sentencia del jefe militar. Juan muere a causa de sus faltas en el ámbito de lo patriarcal, asume que no fue poderoso ni héroe, sino débil y en ello selló la transposición simbólica y debe cumplir con el deber de dicha masculinidad como intento de recuperar lo que le han dicho debía ser.

La ficción en su rol de sujeto moral asume una voz crítica y a la vez moralizante. Por un lado la Cilindra es la heroína en un proceso donde el rol de héroe era exclusivo para los varo- 
nes. Además cumple con el prototipo exaltado de la feminidad, es madre de los cachorros, es afecto, bondad y sacrificio, y desde esta posición simbólica muere en la justa representación del esquema.

La Marota cumple con varios de los sentidos de ser la compañera-esposa, exceptuando aquellos que por su importancia la degradan. Desde la competencia asume la fidelidad a las concepciones del ser mujer pero, al realizar actos propios de lo masculino, debe ser castigada como justa retribución a su infracción y como enseñanza moral a las y los que observan el proceso. El castigo es el precio simbólico, el fruto es la enseñanza y reproducción del modelo.

Juan se mantiene firme ante lo esperado; muere "como hombre", no implora, no suplica, el prototipo del soldado valiente sobrevive a la desobediencia y a la traición. Si bien cometió errores, no perdió dos elementos simbólicos sustanciales de la masculinidad, el dominio de lo femenino, en este caso la Cilindra, y la valentía ante lo ineludible.

En "La Cilindra" se representan formas de ser hombres y mujeres en tiempos revolucionarios, los cuales estaban impregnados de sentidos asumidos desde el pensamiento teológico. La maternidad naturalizada, no elegida y exaltada y la masculinidad propuesta como poder, orden y valentía ante la muerte son esquemas que delinearon las conductas, los juicios y por supuesto el deber ser de los hombres y mujeres de la época. 
El cuento forma parte de lo que hemos Ilamado las tecnologías del género y por ello puede ser comprendida como ficción que contribuye en el proceso de normalizar los prototipos de género. En este marco cobra sentido el objetivo de este análisis, en tanto deconstruir la racionalidad que da sentido a estos prototipos mediante el bosquejo de la aporía existente en los ethos que delinean dichos esquemas.

\footnotetext{
BIBLIOGRAFÍA

AlmazÁn, Laura (2010) "La escritora Carmen Báez cumple 100 años" en "Escenarios" en Cambio de Michoacán. Sociedad Editora de Michoacán S.A. de C.V. 20 de febrero de 2010. Recuperado de http:// www.cambiodemichoacan.com.mx/vernota.php?id=118895

Amorós, Celia (2009) "Rousseau, teórico de la virilidad política" y "Rousseau teórico de la feminidad normativa" en Vetas de Ilustración. Reflexiones sobre feminismo e islam. Madrid: Ediciones Cátedra, pp. 73-78.

BÁEZ, Carmen (1976) "La Cilindra" en Luis Leal [prólogo, notas y selección] Cuentos de la Revolución. México: unAm/Biblioteca del estudiante universitario.

BASTIAN, Jean Pierre (2006) “Modelos de mujer protestante: ideología religiosa" en Escandón, Carmen (Coord.). Presencia y transparencia: la mujer en la historia de México. México: Colmex, pp. 163-180. BUTLER, Judith (2001). El género en disputa. El feminismo y la subversión de la identidad. México: Paidós/PUEG/UnAM.
} 
(2006). Deshacer el género. Barcelona: Paidós.

Cano, Gabriela; Vaughan, Mary y Olcott, Jocelyn (Comps.) (2009) Género, poder y política en el México posrevolucionario. México: FCE.

_ (2006) "Inocultables realidades del deseo. Amelio Robles, masculinidad (transgénero) en la Revolución mexicana" en CANO, Gabriela; VAUGHAN, Mary y OlcotT, Jocelyn (Comps.) (2009). Género, poder y política en el México posrevolucionario. México: FCE, pp. 61-90.

CASAlE, Rolando; CHIACHIO, Cecilia (2009) “Breve recorrido por el pensamiento de Judith Butler" en CASALE, Rolando y CHIACHIO, Cecilia (Comps.). Máscaras del deseo. Una lectura del deseo en Judith Butler. Argentina: Catálogos, pp. 11-37.

De Lauretis, Teresa (1996) “La tecnología del género" en Mora. Núm. 2, Argentina: Universidad de Buenos Aires, pp. 6-34.

Golubov, Nattie (2012) "La crítica feminista posestructural" en La crítica literaria feminista. Una introducción práctica. México: UNAM/Facultad de Filosofía, pp. 71-78.

GonZÁlez, Luis (1980) "De la múltiple utilización de la historia" en Pereyra, Carlos. (Coord.). Historia ipara qué? México: Siglo XXI, pp. 53-74. GamboA, Federico (2001) Santa. México: Época.

KAY, Mary (2009) "Introducción" en Cano, Gabriela; Vaughan, Mary y Olcott, Jocelyn. (Comps.). Género, poder y política en el México posrevolucionario. México: FCE, pp. 39-58

LEAL, Luis (1976) Cuentos de la Revolución. México: UnAm /Biblioteca del Estudiante Universitario.

Miluington, Mark (2007) Hombres in/visibles. Colombia: FCE. Serie Continente Americano. Biblioteca del Estudiante Universitario. 
Monsiváls, Carlos (2009) "Prólogo" en CANO, Gabriela; VAUGHAN, Mary y Olcott, Jocelyn. (Comps.). Género, poder y política en el México posrevolucionario. México: FCE, pp. 11-38.

— (2004). “Crónica de aspectos, aspersiones, cambios, arquetipos y estereotipos de la masculinidad" en Desacatos. Revista de Antropología social. México: CIESAS, pp. 90-108.

— (2000) Aires de familia. Cultura y sociedad en América Latina. México: Anagrama. Colección Argumentos.

Ortega, Aureliano (2011) "Qué pregunta la filosofía desde América" en Ramírez Barreto, Cristina (Coord.) Filosofía desde América: temas, balances y perspectivas. Quito, Ecuador: Editorial Abya Yala.

PÉREZ, Bernardo (2011) "Prototipos semánticos y cognición social en la conformación de identidades" en SÁENZ, Adriana (Coord.). Los prototipos de hombres y mujeres a través de los textos latinoamericanos del siglo XX. México: UMsnh/U de G/UANL, pp. 45-58.

Ramírez, Santiago (2004) El mexicano, psicología de sus motivaciones. México: De Bolsillo.

Rousseau, Juan Jacobo (2007) El Emilio o de la educación. México: Porrúa, Sepan Cuántos. Núm. 159.

Rubenstein, Anne (2006) "La guerra contra las "pelonas". Las mujeres modernas y sus enemigos, Ciudad de México 1924 en CANO, Gabriela; Vaughan, Mary y Olcott, Jocelyn (Comps.) (2009). Género, poder y política en el México posrevolucionario. México: FCE, pp. 91-126.

SÁENZ, Adriana (2015) "La crítica a la racionalidad patriarcal, un paradigma para pensar a los géneros" en ÁvILA, Virginia y SuÁREZ, Paola 
(Coords.) El género y la globalización en los debates de la Teoría Social Contemporánea. México: UnAm, pp. 84-109.

_- (2011) Una mirada a la racionalidad patriarcal en México en los años cincuenta y sesenta del siglo XX. Estudio de la moral en Los años falsos de Josefina Vicens. México: Umsnh/Plaza y Valdés.

THOMPSon, Cooper (2005) "Debemos rechazar la masculinidad tradicional", en Thompson, Keith (editor). Ser hombre. Barcelona: Kairós, Biblioteca de la Nueva Conciencia. $4^{a}$ edición, pp. 28-38.

TuNón, Julia (1998) Mujeres de luz y sombra en el cine mexicano. La construcción de una imagen, 1939-1952. México: El Colegio de México/Instituto Mexicano de Cinematografía. 